\title{
Cascaded Multilevel Inverter with Less Switches
}

\author{
Sujatha M, Krishna Prasad S \\ Assistant Professor Department of Electrical and Electronics Engineering Hindustan University, Chennai, \\ Tamil Nadu, India \\ PG scholar Department of Electrical and Electronics Engineering Hindustan University, Chennai, Tamil Nadu, \\ India
}

\begin{abstract}
The Inverter translates the power from DC to AC. A Multilevel Inverter is a power electronic device that is used for high voltage and high power applications. The level of the needed input voltage depends entirely on the design and purpose of the inverter. This paper proposes a new topology of a cascaded multilevel inverter that utilizes less number of switches than the conventional topology. There will be a reduction in the gate driver circuit with less number of switches.
\end{abstract}

Keywords: PWM technique, Multilevel Inverter, DC, IGBTs.

\section{Introduction}

A power inverter, or inverter, is an electronic device or circuitry that changes Direct Current (DC) to Alternating Current (AC). Multilevel inverter technology [2] has emerged recently as a very important alternative in the area of high-power medium-voltage energy control. The level of the needed input voltage depends entirely on the design and purpose of the inverter. Inverters can be broadly classified into two types; voltage source inverters [3] and current source inverters [3]. A voltage-fed inverter (VFI) or voltage-source inverter (VSI) is one in which the DC source has small impedance or negligible. In other words, a voltage source inverter has stiff DC voltage source at its input terminals. A current-fed inverter (CFI) [3] or current-source inverters (CSI) [3] is fed with adjustable current from a DC source of high impedance, i.e. from a DC current source. In a CSI fed with current source, output current is not affected by the load.

\section{Multilevel Inverter}

Multilevel inverters [2] are significantly different from the ordinary inverter where it generates more than two levels. The semiconductor devices are not connected in series to form one single high-voltage switch. In which each group of devices contribute to a step in the output voltage waveform. The number of switches involved is increased for every level increment. The steps are increased to obtain an almost sinusoidal waveform. The general purpose of the multilevel inverter [2] is to synthesize a nearly sinusoidal voltage from several levels of dc voltages, typically obtained from voltage sources. As the number of level increases, the output waveform has more steps, which produce a step wave that approaches a desired waveform. Also as the number of steps increases, the harmonic distortion of the output waveform decreases, approaching zero as the number of level increases. As the number of level increases, the voltage levels also increases. There are three converter topologies in multilevel inverter. They are,

A) Flying-capacitor multilevel inverter

B) Diode-clamped multilevel inverter

C) Cascaded multilevel inverter

Among the three topologies, cascaded multilevel inverter is an effective one. Cascaded multilevel inverter [1] is having an unique and attractive topology such as simplicity in structure, usage of less number of components, etc.

\subsection{Cascaded Multilevel Inverter}

A cascade multilevel inverter consists of a series of H-bridge (single-phase full bridge) [1] inverter units in each of its three phases. Each H-bridge unit has its own dc source, and for an induction motor it would be a battery unit, fuel cell or solar cell. Each SDC (separate D.C. source) is associated with a single-phase fullbridge inverter. The ac voltage sources of different level inverters are connected in series. The different combinations of the four switches, S1,S2,S3 and S4, each converter level can generate three different voltage outputs, $+\mathrm{Vdc},-\mathrm{Vdc}$ and zero. The $\mathrm{AC}$ outputs of different full-bridge converters in the same phase are connected in series such that the synthesized voltage waveform is the sum of the individual converter outputs. In this technique, the number of output-phase voltage levels is defined by $m=2 \mathrm{~N}+1$, where $\mathrm{N}$ is the number of DC sources. A seven-level cascaded converter, for example, consists of three DC sources and three converter 
bridges. Minimum harmonic distortion can be obtained by controlling the conducting angles at different converter levels [4]. Each $\mathrm{H}$ - bridge unit generates a quasi-square waveform by phase shifting its positive and negative phase legs switching timings. Each device always conducts for $180^{\circ}$ (or half cycle) regardless of the pulse width of the quasi-square wave. This switching method makes all of the switching devices current stress equal.

The advantages of using the cascade inverter in an induction motor include [5]:

(1) It makes induction motor more accessible/safer and open wiring possible for most of an induction motor power system.

(2) Traditional $230 \mathrm{~V}$ or $460 \mathrm{~V}$ motors can be used, thus higher efficiency is expected as compared to low voltage motors.

(3) No EMI problem or common-mode voltage/current problem exists.

(4) Low voltage switching devices can be used.

(5) No charge unbalance problem exists in both charge mode and drive mode.

A cascaded multilevel inverter is used to eliminate the excessively large number of

(1) Bulky transformers required by conventional multi pulse inverters,

(2) Diodes required by multilevel diode-clamped inverters

(3) Capacitors required by multilevel flying-capacitor inverters.

\subsection{Operation of Cascaded Multilevel Inverter}

The converter topology is based on the series connection of single-phase inverters with separate dc sources. Figure 1. shows the power circuit for one phase leg of a three-level, five-level and seven-level cascaded inverter [3]. The resulting phase voltage is synthesized by the addition of the voltages generated by the different cells.

In a 7-level cascaded inverter each single-phase full-bridge inverter generates three voltages at the output: $+\mathrm{Vdc}$, $0,-\mathrm{Vdc}$. This is made possible by connecting the $\mathrm{DC}$ sources sequentially to the $\mathrm{AC}$ side via the power switches. The resulting output $\mathrm{AC}$ voltage is from $-3 \mathrm{Vdc}$ to $+3 \mathrm{Vdc}$ with seven-level inverter. The staircase waveform is nearly sinusoidal, without filtering.

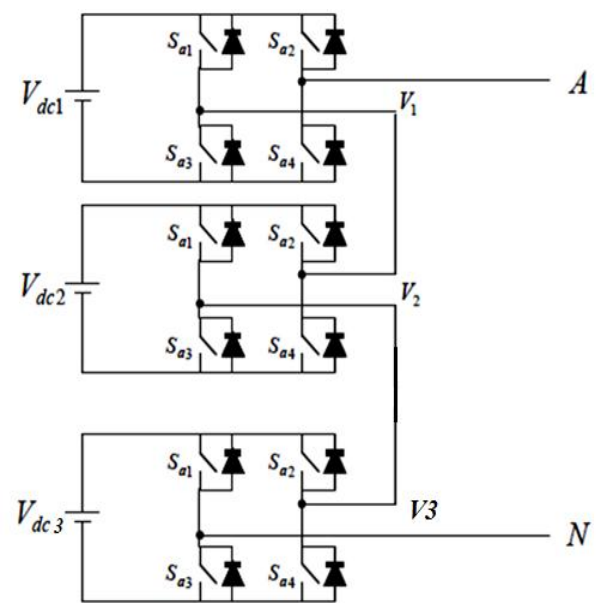

Fig. 1 Cascaded Multilevel Inverter

Table 1: Switches requirement for existing system

\begin{tabular}{|l|c|c|c|c|}
\hline \multicolumn{1}{|c|}{ Parameters } & \multicolumn{4}{c|}{ Cascaded } \\
\hline Levels & 3 & 4 & 5 & 6 \\
\hline Switches required & 12 & 16 & 20 & 24 \\
\hline
\end{tabular}

III. Proposed Multilevel Inverter

The proposed converter consists of less number of switches when compared to the other familiar topologies [1]. The cost reduces because of reduction in the number switch. So, it is an apt one for industrial applications. The general circuit diagram of the proposed multilevel inverter is shown in the figure 2 . The switches are arranged in the sequence as shown in the figure. For the proposed converter, we just need to add only one switch for every increase in levels. So the initial cost is reduced. Let us see operation in the next subdivision in detail for the seven-level inverter. 


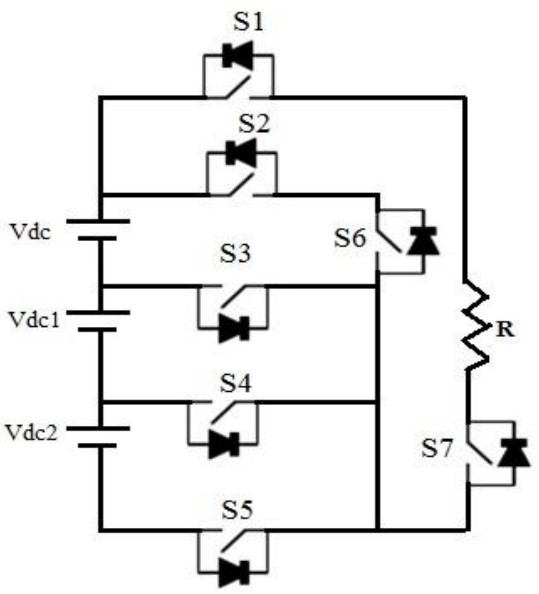

Fig. 2 Proposed System for 7 level

The proposed multilevel inverter for seven levels is shown figure 2.The inverter consists of seven IGBT's switches and three separate DC sources with a load. By switching the IGBT's at the appropriate firing angles, we can obtain the seven level output voltage.

Consider the input supply as 12 volts DC supply. Three various supplies are given individually. By switching the IGBTs, according the table 2 given above,the various levels of output is obtained.

The proposed multilevel inverter for nine levels is shown figure 3.The inverter consists of nine IGBT's switches and four separate DC sources with a load. By switching the IGBT's at the appropriate firing angles, we can obtain the nine level output voltage.

Table 2: Conduction table for proposed system 7 levels

\begin{tabular}{|c|c|c|}
\hline S.NO. & Conducting Switches & $\begin{array}{c}\text { Amplitude Of The } \\
\text { Output Voltage }\end{array}$ \\
\hline 1 & S2, S7, S3 & + Vdc \\
\hline 2 & S2, S7, S4 & $+2 \mathrm{Vdc}$ \\
\hline 3 & S2, S7, S5 & $+3 \mathrm{Vdc}$ \\
\hline 4 & Nil & 0 \\
\hline 5 & S1, S6, S3 & $-\mathrm{Vdc}$ \\
\hline 6 & S1, S6, S4 & $-2 \mathrm{Vdc}$ \\
\hline 7 & S1, S6, S5 & $-3 \mathrm{Vdc}$ \\
\hline
\end{tabular}

Consider the input supply as 12 volts DC supply. Three various supplies are given individually. By switching the IGBTs, according the table 3 given above ,the various levels of output is obtained.

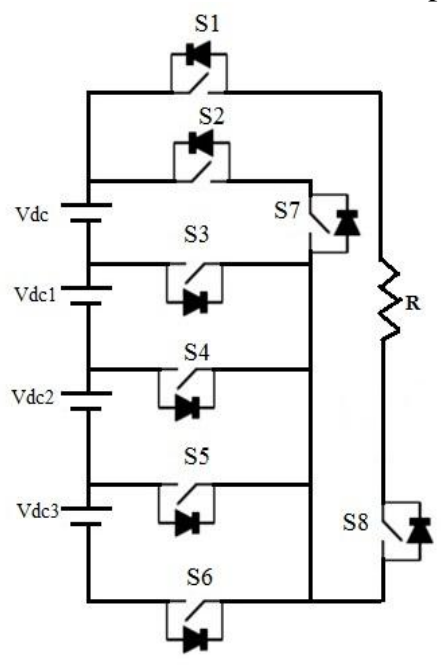

Fig. 3 Circuit diagram for 9-level proposed system

Table 3: Conduction table for proposed system 9levels

\begin{tabular}{|c|c|c|}
\hline S.NO. & Conducting Switches & $\begin{array}{c}\text { Amplitude Of The } \\
\text { Output Voltage }\end{array}$ \\
\hline 1 & S2, S8, S3 & + Vdc \\
\hline
\end{tabular}




\begin{tabular}{|c|c|c|}
\hline 2 & S2, S8, S4 & $+2 \mathrm{Vdc}$ \\
\hline 3 & S2, S8, S5 & $+3 \mathrm{Vdc}$ \\
\hline 4 & S2, S8, S6 & $+4 \mathrm{Vdc}$ \\
\hline 5 & Nil & 0 \\
\hline 6 & S1, S7, S3 & $-\mathrm{Vdc}$ \\
\hline 7 & $\mathrm{~S} 1, \mathrm{~S} 7, \mathrm{~S} 4$ & $-2 \mathrm{Vdc}$ \\
\hline 8 & $\mathrm{~S} 1, \mathrm{~S} 7, \mathrm{~S} 5$ & $-3 \mathrm{Vdc}$ \\
\hline 9 & $\mathrm{~S} 1, \mathrm{~S} 7, \mathrm{~S} 6$ & $-4 \mathrm{Vdc}$ \\
\hline
\end{tabular}

\section{Comparison Of Proposed Multilevel Inverter And Cascaded Multilevel Inverter}

The table 4 shows the comparison between the proposed inverter with the cascaded multilevel inverter [1] [2]. The proposed inverter exhibits a significant outcome such as reduction in the number of switches and an easy control is possible.

Table 4 : Comparison of cascaded multilevel inverter and proposed multilevel inverter based on number of switches

\begin{tabular}{|l|c|c|c|c|}
\hline \multicolumn{1}{|c|}{ Parameters } & \multicolumn{4}{|c|}{ Cascaded } \\
\hline Levels & 3 & 4 & 5 & 6 \\
\hline $\begin{array}{l}\text { Switches } \\
\text { required }\end{array}$ & 12 & 16 & 20 & 24 \\
\hline
\end{tabular}

\begin{tabular}{|c|c|c|c|c|}
\hline Parameters & \multicolumn{4}{|c|}{ Proposed } \\
\hline Levels & 3 & 4 & 5 & 6 \\
\hline $\begin{array}{l}\text { Switches } \\
\text { required }\end{array}$ & 7 & 8 & 9 & 10 \\
\hline
\end{tabular}

\section{Simulation}

MATLAB is an interactive system whose basic data element is an array that does not require dimensioning. This allows to solve many technical computing problems.

MATLAB features a family of add-on application-specific solutions called toolboxes. It is a comprehensive collections of MATLAB function (M-file) that extend the MATLAB environment to solve particular classes of problems.

Simulink is a tool for modeling, simulating and analyzing multi domain dynamic systems. Its primary interface is a graphical block diagramming tool and a customizable set of block libraries.

For modeling, Simulink provides a graphical user interface (GUI) for building models as block diagram, using click-and drag mouse operations. Simulink includes a comprehensive block library of sinks, sources, linear and nonlinear components, and connectors. We can also customize and create our own blocks.

After defining a model, we can simulate it, using a choice of integration methods, either from the simulink menus or by entering commands in the MATLAB command window. Using scope and other display blocks, we can see the simulation results while the simulation is running.

The simulation results can be put in the MATLAB workspace for post processing and visualization. Since, MATLAB [5] and simulink are integrated, we can simulate,

Analyze, and revise your model in either environment at any point. 


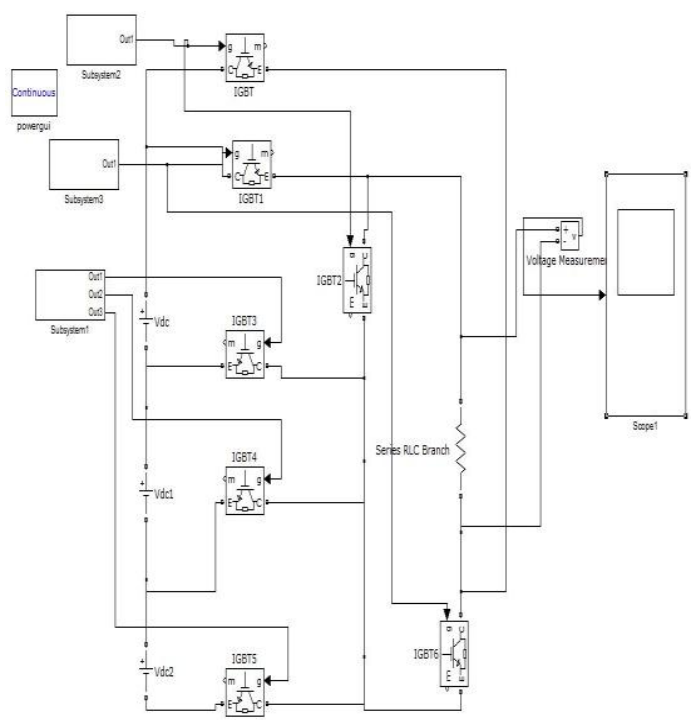

Fig. 4 Proposed System circuit for 7 levels

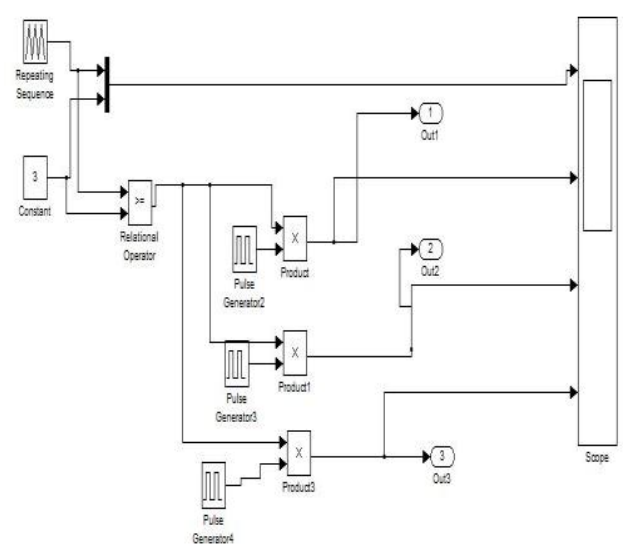

Fig. 5 PWM circuit of Switches S3,S4,S5

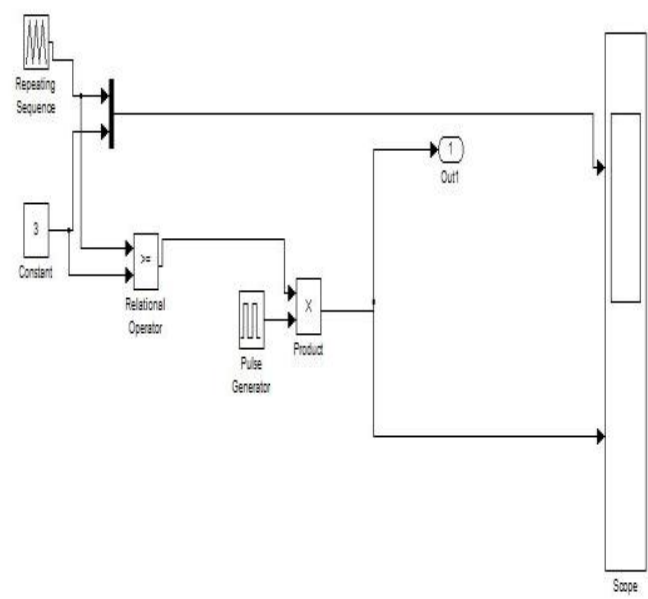

Fig. 6 PWM circuit of Switches S1,S6 


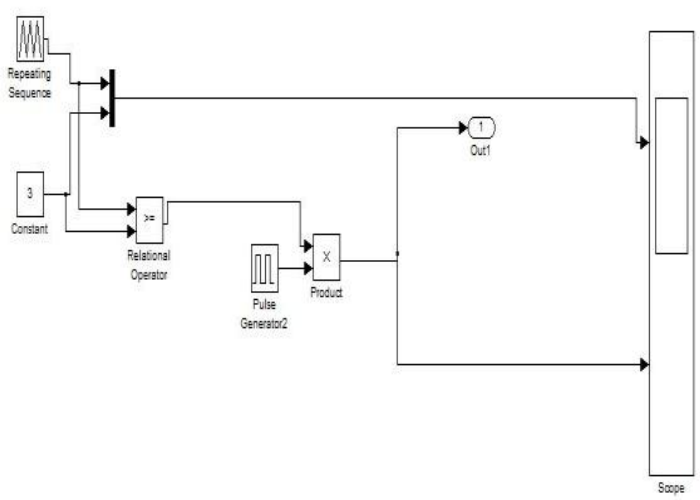

Fig. 7 PWM circuit of Switches S2,S7

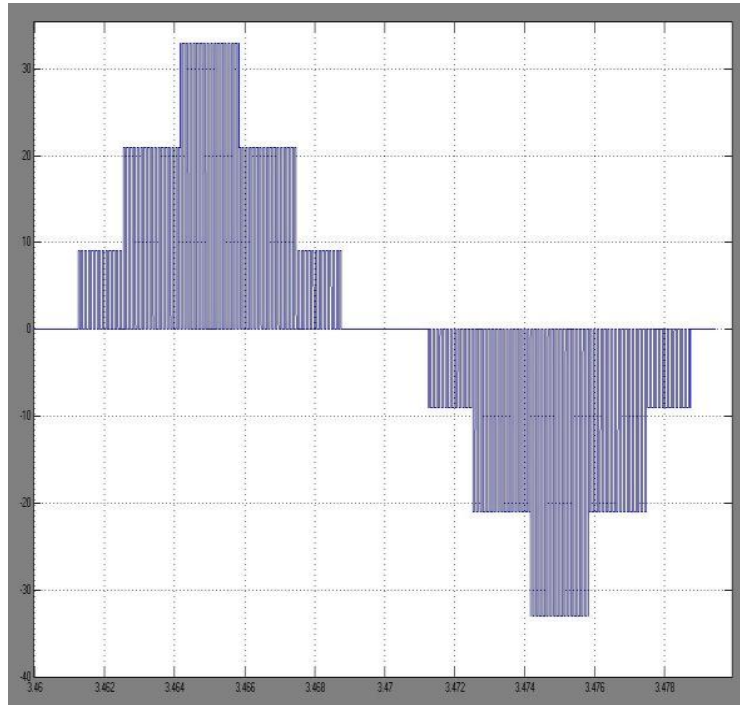

Fig. 8 Output of Proposed System for 7 levels

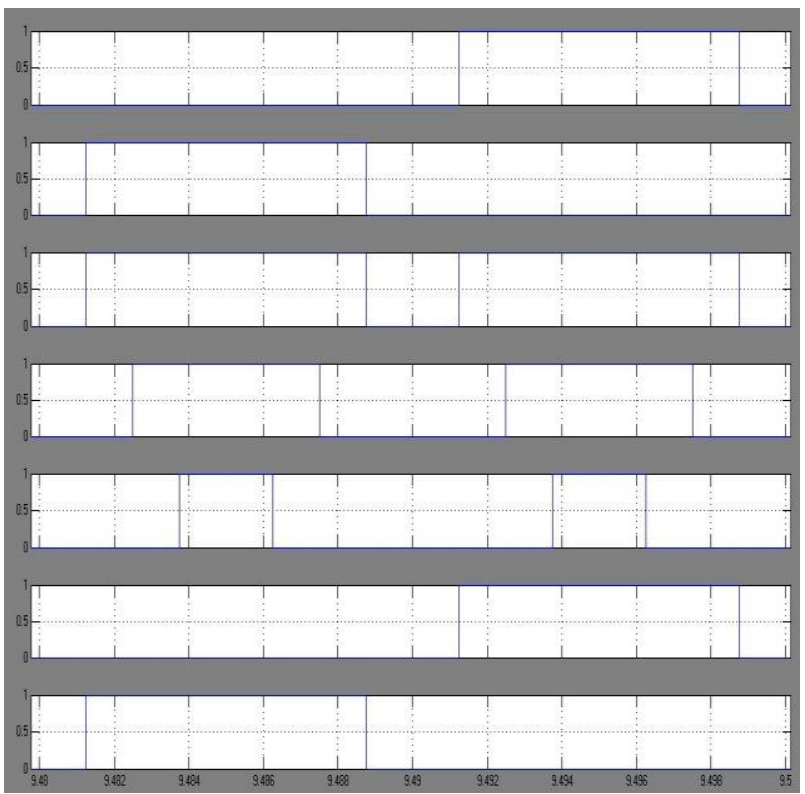

Fig. 9 Pulse Generator Pulses for switches S1 to S7 


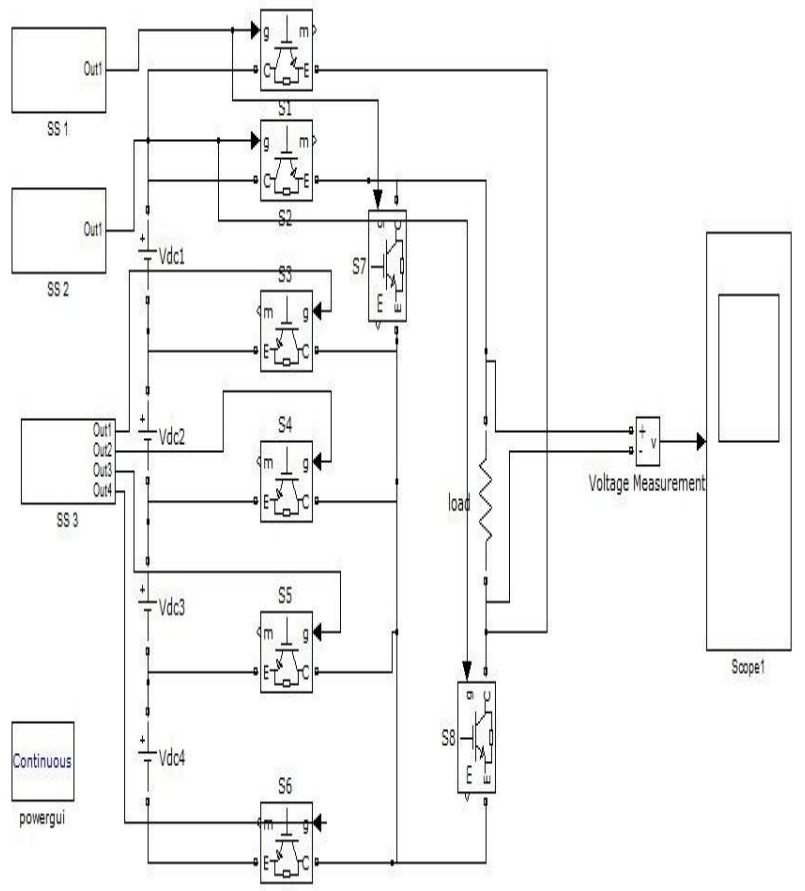

Fig. 10 Proposed system circuit for 9 levels

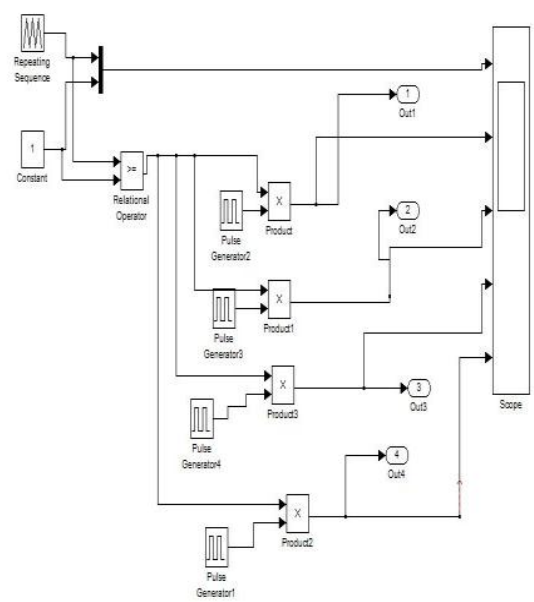

Fig. 11 PWM circuit for S3,S4,S5,S6

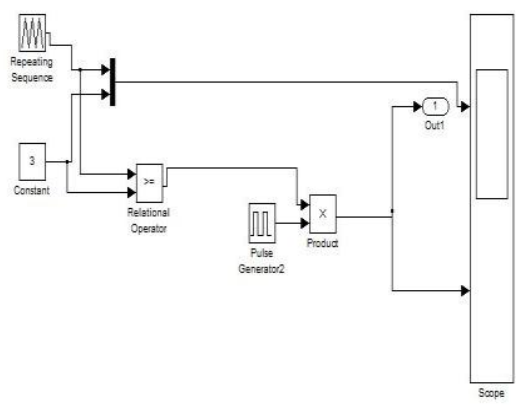

Fig. 12 PWM circuit for S1,S7 


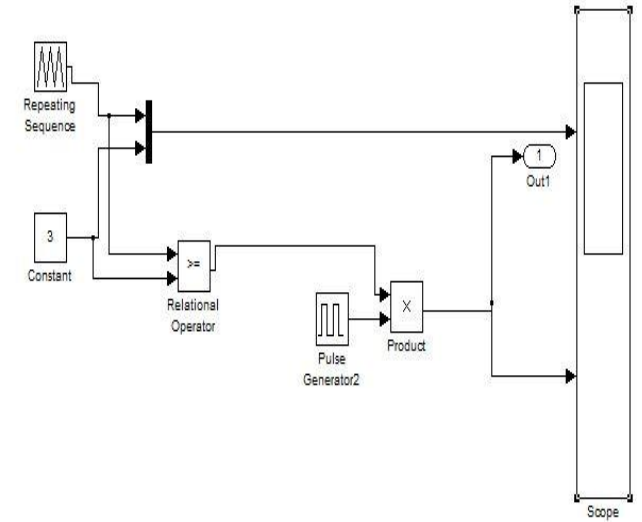

Fig. 13 PWM circuit for S2,S8

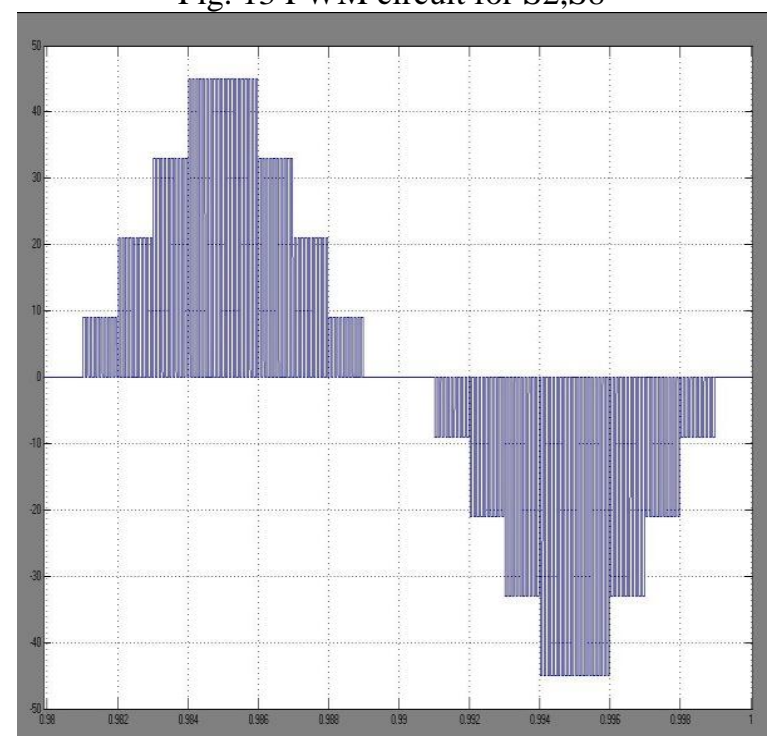

Fig. 14 Output of Proposed system for 9 levels

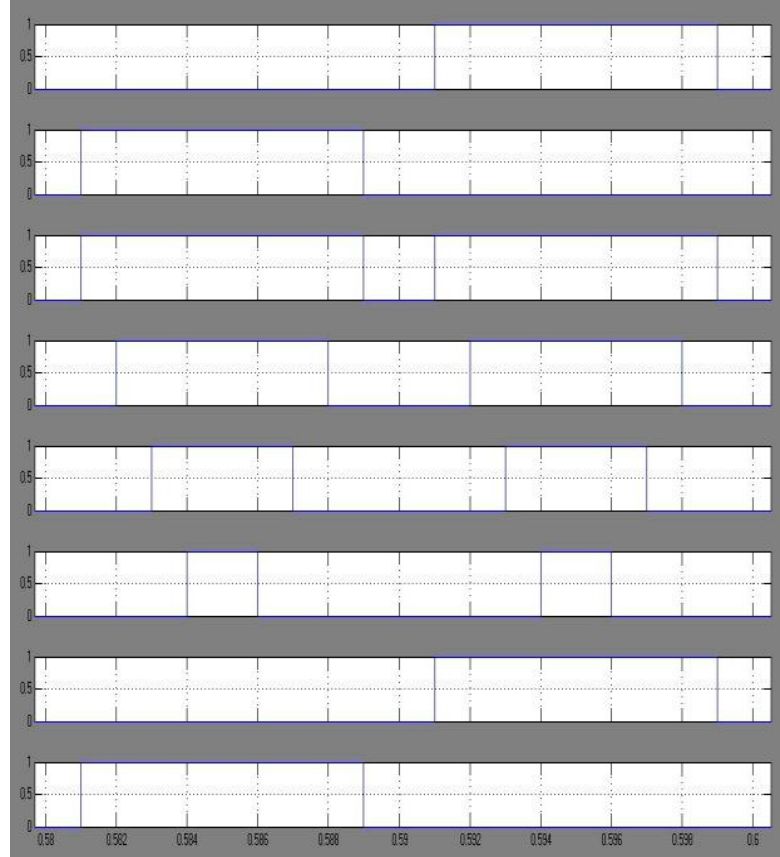

Fig. 15 Pulse generator pulses for switches S1 to S8 


\section{Conclusion}

When we increase the levels, the number of switches used is very less compared to the other topology. The simulation of the seven-level multilevel inverter is successfully done using pulse width modulation technique. From the simulation, it is noted that the new multilevel inverter topology works well and shows hope to reduce the initial cost and complexity.

\section{References}

[1]. Ebrahim Babaei, 2008, “A Cascade Multilevel Converter Topology With Reduced Number of Switches" IEEE Transactions on power electronics, Vol. 23, No.6.

[2]. J. Rodríguez, J. S. Lai, and F. Z. Peng, "Multilevel inverters: A survey of topologies, controls, and applications," IEEE Transaction on Industrial electronics, vol. 49, no. 4, pp. 724-738, Aug. 2002

[3]. Rashid, M.H, 2004. "Power Electronics:Circuits, devices and applications. Third Edition, Prentice Hall.

[4]. L. M. Tolbert, F. Z. Peng, T. G. Habetler, "Multilevel PWM methods at low modulation indices," IEEE Transactions on power electronics, vol. 15, no. 4, July 2000, pp. 719-725.

[5]. Mohan N, Undeland T. M, and Robbins W.P. 2003, Power Electronics: converters, applications and design”, Third Edition.John Wiley and sons. 